\title{
Rhabdomyolysis in Clozapine Overdose
}

\author{
Frank G. A. Jansman ${ }^{1,2}$ - Heleen A. Crommelin ${ }^{1}$ - Freek J. A. H. van Hout ${ }^{3}$. \\ Jan Meulenbelt ${ }^{4}$
}

Published online: 2 July 2015

(C) The Author(s) 2015. This article is published with open access at Springerlink.com

\begin{abstract}
Context Clozapine is used for decennia for the treatment of schizophrenia. Agranulocytosis, diabetic ketoacidosis, gastrointestinal hypomotility, and myocarditis are wellknown adverse effects of clozapine, which are sometimes life threatening. Here we report a case of rhabdomyolysis upon an acute overdose of clozapine.

Case A male patient, 36 years, with elevated creatinine kinase levels (9899 U/l), developed rhabdomyolysis afterafter admission to the emergency department. Approximately $2-4 \mathrm{~h}$ earlier he had intoxicated himself with his maintenance oral medication clozapine $125 \mathrm{mg}$, temazepam $20 \mathrm{mg}$ and lorazepam $1.5 \mathrm{mg}$. Co-medications, and physical and laboratory examinations did not reveal other risk factors for rhabdomyolysis. According to the Naranjo probability scale there was a probable relation between clozapine dose and symptoms, that developed approximately $2-4 \mathrm{~h}$ after the auto-intoxication of $125 \mathrm{mg}$ tablets. At day 5 of hospitalization, clozapine and creatinine kinase levels returned to normal and the patient was discharged with no somatic sequelae.
\end{abstract}

Frank G. A. Jansman

f.g.a.jansman@dz.nl

1 Department of Clinical Pharmacy, Deventer Hospital, Nico Bolkesteinlaan 75, Deventer 7416 SE, The Netherlands

2 Department of Pharmacotherapy and Pharmaceutical Care, University of Groningen, Groningen, The Netherlands

3 Department of Emergency Medicine, Deventer Hospital, Deventer, The Netherlands

4 Department of Intensive Care Center and National Poisons Information Center, University Medical Center Utrecht, Utrecht, The Netherlands
Conclusions Elevated creatinine kinase levels in acute clozapine intoxication may be an indicator that rhabdomyolysis may be involved.

\section{Key Points}

Rhabdomyolysis may occur upon an acute overdose of clozapine.

Elevated creatinine kinase levels in acute clozapine overdose may be associated with the development of rhabdomyolysis.

Rhabdomyolysis with elevated clozapine and creatinine kinase levels may be reversible.

\section{Case Report}

Clozapine is an atypical antipsychotic drug that is used in patients who have not responded adequately to treatment with standard drug treatments for schizophrenia. Its use is limited by agranulocytosis, a rare but potentially lifethreatening adverse event. We describe a case of rhabdomyolysis upon an acute overdose of clozapine.

A 36-year-old man with a history of schizophrenia was admitted to the emergency department of our hospital because of altered consciousness and disorientation. According to the patient and his accompanying brother, he had intoxicated himself in the previous $2-4 \mathrm{~h}$ with his current maintenance medication, i.e., clozapine $125 \mathrm{mg}$, temazepam $20 \mathrm{mg}$, and lorazepam $1.5 \mathrm{mg}$, all prescribed once daily. The medical anamnesis did not reveal other medicines being used. He was known for excessive 
smoking and alcohol ingestion (an estimated intake of 15 units daily).

His initial Glasgow Coma Score was 14 (E4M6V4). The patient was agitated and delirious. He was tachycardic with a pulse of 145/min, blood pressure of 166/109 $\mathrm{mmHg}$, and a respiration rate of $22 / \mathrm{min}$. Serum creatinine kinase (CK) $9899 \mathrm{U} / \mathrm{L}$, aspartate aminotransferase $305 \mathrm{U} / \mathrm{L}$, alanine aminotransferase $59 \mathrm{U} / \mathrm{L}$, and lactate dehydrogenase $417 \mathrm{U} / \mathrm{L}$ were elevated. C-reactive protein was slightly elevated at $38 \mathrm{mg} / \mathrm{L}$. Potential other contributors to muscle damage such as seizures or compartment syndrome were absent. Ethanol was not detectable. Arterial blood gas analysis showed an elevated $\mathrm{pH} 7.49, \mathrm{pO}_{2} 3.9 \mathrm{kPa}, \mathrm{pCO}_{2} 18.2 \mathrm{kPa}$, and bicarbonate $22 \mathrm{mmol} / \mathrm{L}$. ECG was normal. Urine analyses for amphetamines, cocaine, methadone, opioids, and cannabis were negative. Urine infection was excluded. Chest X-ray and computed tomography scan of the brain were both normal.

The initial treatment consisted of $1 \mathrm{~L}$ of normal saline in $1 \mathrm{~h}$, an additional $100 \mathrm{~mL}$ of sodium bicarbonate $8.4 \%$, followed by $4 \mathrm{~L}$ of normal saline in the next $6 \mathrm{~h}$, for rhabdomyolysis, thiamine $100 \mathrm{mg}$ intramuscularly for chronic alcohol abuse, and lorazepam $1 \mathrm{mg}$ intravenously for agitation and ethanol withdrawal symptoms.

Approximately $10 \mathrm{~h}$ after arrival at the emergency department, analysis revealed extremely high plasma clozapine concentrations of $3177 \mu \mathrm{g} / \mathrm{L}$ (reference values: 200-600 $\mu \mathrm{g} / \mathrm{L}$ ), and normal concentrations of temazepam and lorazepam of $0.19 \mathrm{mg} / \mathrm{L}$ (reference values: $0.10-0.80 \mathrm{mg} / \mathrm{L}$ ) and $0.14 \mathrm{mg} / \mathrm{L}$ (reference values: $0.02-0.25 \mathrm{mg} / \mathrm{L}$ ), respectively. He was transferred to our intensive care unit for further treatment.

After 2 days, CK decreased to $3450 \mathrm{U} / \mathrm{L}$. The clozapine plasma concentration decreased to non-toxic concentrations $(153 \mu \mathrm{g} / \mathrm{L}) 5$ days after hospitalization (Fig. 1). After a psychiatric evaluation, the patient was discharged with no somatic sequelae.

Clozapine is an antipsychotic drug with potentially harmful adverse effects. The most frequently reported symptoms in clozapine intoxication are impaired alertness and tachycardia [1]. Also known, but scarcely reported, are extremely high CK levels and rhabdomyolysis [2]. It is important to recognize rhabdomyolysis in time to prevent acute renal failure [3].

Another cause of rhabdomyolysis in relation to clozapine is a neuroleptic malignant syndrome, a potentially lifethreatening but rare condition occurring in psychiatric patients receiving neuroleptic agents [4]. However, our patient showed no hyperthermia or muscle rigidity and did not meet the Diagnostic and Statistical Manual of Mental DisordersFourth Edition criteria. Furthermore, the co-medication of temazepam and lorazepam is not likely to be associated with rhabdomyolysis because these agents have no clinically relevant interaction with clozapine; benzodiazepines solely have been described to be related to this side effect. However, in the present case, the immobilization secondary to the clozapine overdose and delirium tremens due to alcohol abstinence cannot be excluded as contributing factors to the development or augmentation of rhabdomyolysis.

According to the Naranjo probability scale [5], there was a probable relationship, i.e., score 6 , between the development of rhabdomyolysis and clozapine overdose in this patient. This score was calculated from the results of previous conclusive reports on the reaction $(+1)$, appearance after the drug was given $(+2)$, improvement on discontinuation $(+1)$, alternative causes $(-1)$, toxic concentrations $(+1)$, reaction less severe when exposure decreased $(+1)$, and confirmation of the adverse event by objective evidence, i.e., manifest rhabdomyolysis and elevated concentrations $(+1)$.
Fig. 1 Patient clozapine and creatinine kinase (CK) concentrations during 5 days of hospitalization

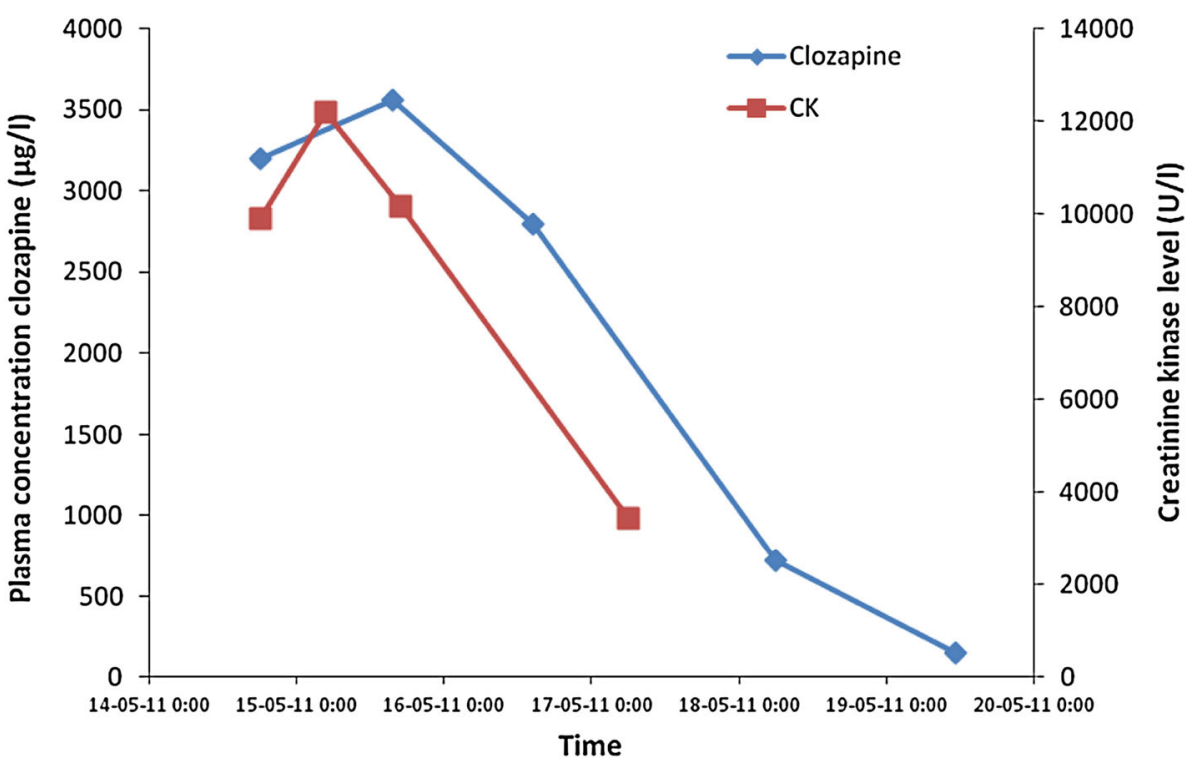


In conclusion, when $\mathrm{CK}$ levels are elevated in patients treated for an overdose with clozapine, rhabdomyolysis should be considered.

\section{Compliance with ethical standards}

Conflict of interest Frank G. A. Jansman, Heleen A. Crommelin, Freek J. A. H. van Hout, and Jan Meulenbelt declare that they have no conflict of interest.

Study funding No financial support was received for the conduct of this study or preparation of this manuscript.

Informed consent Written informed consent was obtained from the patient for publication of this case report. A copy of the written consent is available for review by the Editor-in-Chief of this journal.

Open Access This article is distributed under the terms of the Creative Commons Attribution-NonCommercial 4.0 International License (http://creativecommons.org/licenses/by-nc/4.0/), which permits any noncommercial use, distribution, and reproduction in any medium, provided you give appropriate credit to the original author(s) and the source, provide a link to the Creative Commons license, and indicate if changes were made.

\section{References}

1. Le Blaye I, Donatini B, Hall M, Krupp P. Acute overdosage with clozapine: a review of the available clinical experience. Pharm Med. 1992;6:169-78.

2. Gupta GB, Sahu MK. Myotoxicity in acute clozapine overdose. Int J Psychiatr Clin Pract. 2006;10:303-4.

3. Grossman RA, Hamilton RW, Morse BM, Penn AS, Golberg M. Nontraumatic rhabdomyolysis and acute renal failure. $\mathrm{N}$ Engl $\mathrm{J}$ Med. 1974;291:807-11.

4. Pelonero AL, Levenson JL, Pandurangi AK. Neuroleptic malignant syndrome: a review. Psychiatr Serv. 1998;49:1163-72.

5. Naranjo CA, Busto U, Sellers EM, Sandor P, Ruiz I, Roberts EA, Nanecek E, Domecq C, Greenblatt DJ. A method for estimating the probability of adverse drug reactions. Clin Pharmacol Ther. 1981;30:239-45. 